\title{
Is aortic wall degeneration related to bicuspid aortic valve anatomy in patients with valvular disease?
}

\author{
Claudio F. Russo, MD, ${ }^{a}$ Aldo Cannata, MD, ${ }^{a}$ Marco Lanfranconi, MD, ${ }^{a}$ Ettore Vitali, MD, ${ }^{a}$ Andrea Garatti, MD, \\ and Edgardo Bonacina, $\mathrm{MD}^{\mathrm{b}}$
}

From the Angelo De Gasperis Department of Cardiac Surgery, ${ }^{\mathrm{a}}$ and Pathology Department, ${ }^{\mathrm{b}}$ Niguarda Cà Granda Hospital, Piazza Ospedale Maggiore, Milan, Italy.

Received for publication July 10, 2007; revisions received Nov 13, 2007; accepted for publication Nov 26, 2007.

Address for reprints: Aldo Cannata, MD, Angelo De Gasperis Department of Cardiac Surgery, Niguarda Cà Granda Hospital, Piazza Ospedale Maggiore, 3. 20162, Milan, Italy (E-mail: aldo.cannata@libero.it).

J Thorac Cardiovasc Surg 2008;136:937-42 0022-5223/\$34.00

Copyright $\odot 2008$ by The American Association for Thoracic Surgery

doi:10.1016/j.jtcvs.2007.11.072
Objective: Patients with bicuspid aortic valve are at increased risk for aortic complications.

Methods: A total of 115 consecutive patients with bicuspid aortic valve disease underwent surgery of the ascending aorta. We classified the cusp configuration by 3 types: fusion of left coronary and right coronary cusps (type A), fusion of right coronary and noncoronary cusps (type B), and fusion of left coronary and noncoronary cusps (type C). Histopathologic changes in the ascending aortic wall were graded (aortic wall score).

Results: We observed type A fusion in 85 patients (73.9\%), type B fusion in 28 patients $(24.3 \%)$, and type $\mathrm{C}$ fusion in 2 patients (1.8\%). Patients with type A fusion were younger at operation than patients with type B fusion $(51.3 \pm 15.5$ years vs $58.7 \pm 7.6$ years, respectively; $P=.034$ ). The mean ascending aorta diameter was $48.9 \pm 5.0 \mathrm{~mm}$ and $48.7 \pm 5.7 \mathrm{~mm}$ in type A and type B fusion groups, respectively $(P=.34)$. The mean aortic root diameter was significantly larger in type A fusion (4.9 $\pm 6.7 \mathrm{~mm}$ vs $32.7 \pm 2.8 \mathrm{~mm} ; P<.0001)$. The aortic wall score was significantly higher in type A fusion than in type $\mathrm{B}$ fusion $(P=.02)$. The prevalence of aortic wall histopathologic changes was significantly higher in type A fusion. Moreover, there were no statistically significant differences between type A and type B fusion in terms of prevalence of bicuspid aortic valve stenosis, regurgitation, or mixed disease.

Conclusion: In diseased bicuspid aortic valves, there was a statistically significant association between type A valve anatomy and a more severe degree of wall degeneration in the ascending aorta and dilatation of the aortic root at younger age compared with type B valve anatomy.

B icuspid aortic valve (BAV) is one of the most common congenital diseases involving the heart valves, with a prevalence ranging from $1 \%$ to $2 \%$ of the entire population. More important, it is associated with an increased lifelong risk of aortic valve dysfunction and endocarditis, requiring surgery. ${ }^{1}$ Furthermore, data from several groups, including our own, ${ }^{2-4}$ demonstrated that patients with $\mathrm{BAV}$ are at increased risk for aortic complications, even late after aortic valve surgery, because of histopathologic changes in the ascending aorta, predisposing one to aneurysm development and dissection. . $^{5-7}$

The aim of the study is to investigate the relationships between aortic valve anatomy and histopathology of the aortic wall in a series of patients affected by BAV and undergoing replacement of the ascending aorta.

\section{Materials and Methods \\ Study Group}

After authorization from the hospital review board, we reviewed our computerized database and identified 115 consecutive patients who underwent surgery on both the BAV and the ascending aorta between January of 2003 and November of 2006 at the Niguarda Cà Granda Hospital. We 


\section{Abbreviations and Acronyms}

AWS $=$ aortic wall score

$\mathrm{BAV}=$ bicuspid aortic valve

did not include patients who underwent isolated surgery of the aortic valve without resection and histologic examination of the ascending aorta or patients undergoing surgery for type A aortic dissection. The mean age was $55.2 \pm 15.6$ years (range: $12-80$ years), the mean body surface area was $1.81 \pm 0.24 \mathrm{~m}^{2}$ (range: $1.6-2.2 \mathrm{~m}^{2}$ ), and 18 patients $(15.6 \%)$ were female. All patients were affected by BAV severe stenosis, regurgitation, or a combination of both that required concomitant valve replacement or repair. No patients were affected by frank Marfan syndrome, according to Ghent criteria, ${ }^{8}$ or had a history of rheumatic heart disease.

\section{Anatomic Definition of Bicuspid Aortic Valve}

The diagnosis of BAV was made preoperatively by means of 2- or 3-dimensional transthoracic echocardiography. The diagnosis was confirmed during intraoperative surgical inspection of the aortic valve, according to previous anatomic descriptions. ${ }^{9,10}$ We reviewed operative reports for all patients to obtain the pattern of cusp fusion and aortic diameter. The position of any raphe was recorded.

\section{Ascending Aorta and Aortic Root Diameters}

Transverse diameter of both the mid-ascending aorta above the sinotubular junction and the aortic root at the Valsalva sinuses were measured in all patients both preoperatively (by means of computed tomography and echocardiography) and during the operation (by means of direct measurement and transesophageal echocardiography). We recorded the highest measured diameter.

\section{Indications to the Operation}

In 2001, after the observation of increased incidence of aortic complications at long-term after BAV surgery, ${ }^{2}$ we adopted an aggressive policy to replace dilated ascending aortas or aortic roots in patients with BAV. The threshold diameter to replace the aorta is between 40 and $45 \mathrm{~mm}$, according to clinical status and surgeon preference. In case of significant displacement of the coronary ostia from the aortic anulus, we replaced the entire aortic root by implantation of a composite valved-graft (modified Bentall technique) or by a valve-sparing operation, according to cusp status and surgeon preference. We elected to perform a Ross operation only in children.

\section{Histopathologic Examination}

Circumferential aortic wall samples, from the mid-ascending aorta at the point of maximal dilatation, were fixed in formalin for 24 hours. The tissue was processed for light microscopy and embedded in paraffin blocks, and sections were taken from each specimen. Sections were stained with hematoxylin-eosin and Masson trichrome stains. In all cases, histologic examination was performed in an unblinded way by one of the authors (E.B.) along the full length of the circumferential aortic wall samples. Histopathologic changes were graded according to criteria published by Matthias Bechtel and coworkers. ${ }^{5}$ In brief, 7 pathologic features of the aortic wall, namely, fibrosis, atherosclerosis, medionecrosis, cystic medial necrosis, smooth muscle cell orientation, elastic fragmentation, and inflammation, were analyzed in each specimen and graded using a scale from 0 (no pathologic changes) to 3 (most severe changes). Grading was determined on the basis of the worst area observed. The sum of the results of all variables was calculated in each patient, and this is the aortic wall score (AWS).

\section{Statistical Analysis}

Categoric variables are expressed as total numbers and percentages. Continuous variables are expressed as means \pm standard deviation. In case of continuous nonparametric variables, as shown by the Kolmogorov-Smirnov test, we reported data as median and interquartile range. Comparison of categoric variables was performed with the chi-square test or Fisher's exact test, as appropriate, and continuous variables were analyzed with the Student $t$ test or Mann-Whitney test, as appropriate.

\section{Results}

\section{Overall Population}

In all cases, we observed only 1 raphe in each aortic valve. Therefore, we classified BAV anatomy in 3 types according to raphe orientation in relation to the sinuses and cusp fusion pattern (Figure 1): fusion of left coronary and right coronary cusps (type A), fusion of right coronary and noncoronary cusps (type B), and fusion of left coronary and noncoronary cusp (type C). We observed type A fusion in 85 patients (73.9\%), type B fusion in 28 patients $(24.3 \%)$, and type C fusion in 2 patients $(1.8 \%)$ (Figure 1). Because of the low prevalence of type $\mathrm{C}$ fusion in this series, we elect to exclude it from further comparisons with the other 2 patterns. The mean ascending aorta diameter was $49.5 \pm 8.9 \mathrm{~mm}$ (range $38-80 \mathrm{~mm}$ ). The aortic root diameter at the Valsalva sinuses

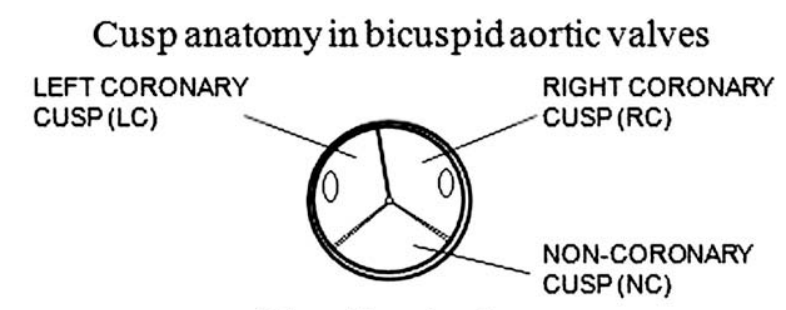

Tricuspid aortic valve

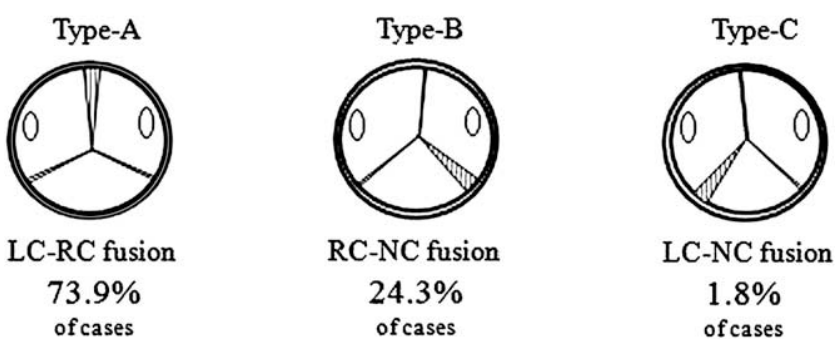

Figure 1. Shaded area shows the position of the raphe on the valve. $L C-N C$, Left coronary-noncoronary cusp; $L C-R C$, left coronary-right coronary cusp; $R C-N C$, right coronary-noncoronary cusp. 
was $40.25 \pm 6.49 \mathrm{~mm}$ (range $28-55 \mathrm{~mm}$ ). The mean AWS was $7.8 \pm 4.4$ (range $3-21$ ). There was a correlation between ascending aorta diameter and AWS $(r=0.5723)$ in our series of patients affected by both BAV disease and aortic aneurysm (Figure 2). The surgical procedures are shown in Table 1. The in-hospital mortality was $1.7 \%(2 / 115)$.

\section{Comparisons Between Type A and Type B Fusion}

Comparisons between type $\mathrm{A}$ and type $\mathrm{B}$ fusion are reported in Table 2. Patients with type A fusion were younger at operation than patients with type $\mathrm{B}$ fusion (mean age $51.3 \pm 15.5$ years vs $58.7 \pm 7.6$ years, respectively, $P=.034$; median age 52 vs 61 years, respectively; range 16-74 years vs 44-75 years, respectively). The mean ascending aorta diameter did not differ significantly between type A and type B groups. However, in type $\mathrm{A}$ the mean aortic root diameter was significantly larger $(P<.0001)$. Moreover, there were no statistically significant differences between type A fusion and type B fusion in terms of prevalence of BAV stenosis, regurgitation, mixed disease, and arterial hypertension. Median (interquartile range) AWS was significantly higher in type A fusion than in type B fusion (6 [3-9] vs 3 [1-4], $P<.001$ ). The prevalence of fibrosis, medionecrosis, cystic medial necrosis, smooth muscle cell orientation, elastic fragmentation, and inflammation (grade $\geq 1$ ) was significantly higher in type A fusion compared with type B fusion (Table 3). However, we did not observe any statistically significant difference in terms of atherosclerosis. Figure 3 shows histologic sections from the ascending aorta of patients with type A anatomy and patients with type B anatomy.

\section{Discussion}

\section{Anatomic and Histopathologic Evidence}

The main observations derived from the study on patients affected by both BAV disease and aortic dilatation are as follows:

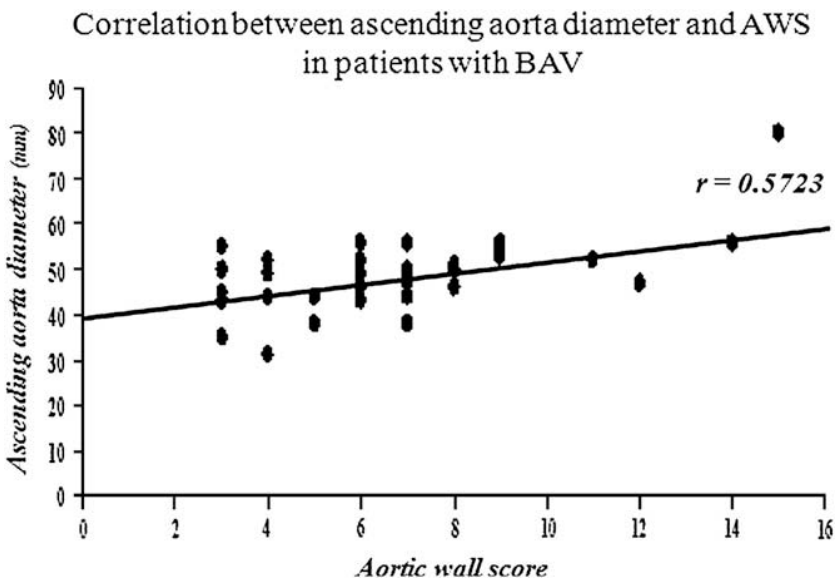

Figure 2. Correlation between ascending aorta diameter and AWS in patients with BAV.
TABLE 1. Surgical techniques

\begin{tabular}{lrr}
\hline & $\mathbf{n}$ & $\%$ \\
\hline $\begin{array}{l}\text { Combined AVR and ascending } \\
\quad \text { aorta replacement }\end{array}$ & 29 & 25.2 \\
$\begin{array}{lr}\text { Combined AVRep and ascending } \\
\quad \text { aorta replacement }\end{array}$ & 1 & 0.9 \\
Modified Bentall operation & 79 & 68.7 \\
David operation & 5 & 4.3 \\
Ross operation & 1 & 0.9 \\
Other combined procedures & & \\
AF surgery & 1 & \\
CABG & 16 & \\
MVR & 6 & \\
ASD repair & 1 &
\end{tabular}

$A V R$, Aortic valve replacement; $A V R e p$, aortic valve repair; $A F$, atrial fibrillation; $C A B G$, coronary artery bypass grafting; $M V R$, mitral valve replacement; $A S D$, atrial septal defect.

1. Type A cusp fusion is the most common configuration observed in BAV, followed by type B.

2. Type A cusp fusion is associated with a more severe degree of degeneration of the ascending aorta wall, even in the absence of significant differences with type B group in terms of ascending aorta diameter, $\mathrm{BAV}$ disease, and prevalence of arterial hypertension; nevertheless, the mean age of patients with type A was significantly lower than that of patients with type B. Moreover, in type A fusion the aortic root diameter was significantly larger than in type B fusion.

3. The degree of aortic wall degeneration is directly related to the ascending aorta diameter.

Our anatomic data confirm previous evidence on the configuration of aortic valve cusps in BAV. In a surgical pathology study including 542 cases of BAV, Sabet and coworkers ${ }^{10}$ reported a prevalence of $86 \%$ for type A fusion, compared with $12 \%$ for type B. In an echocardiographic

\section{TABLE 2. Features of type A and type B cusp fusion}

\begin{tabular}{lccc}
\hline & $\begin{array}{c}\text { Type A } \\
\mathbf{N = 8 5}\end{array}$ & $\begin{array}{c}\text { Type B } \\
\mathbf{n = 2 8}\end{array}$ & $\boldsymbol{P}$ \\
\hline $\begin{array}{l}\text { Ascending aorta } \\
\quad \text { diameter, mean } \pm \mathrm{SD}\end{array}$ & $48.9 \pm 5.0 \mathrm{~mm}$ & $48.7 \pm 5.7 \mathrm{~mm}$ & $\mathrm{NS}$ \\
$\begin{array}{l}\text { Aortic root } \\
\quad \text { diameter, mean } \pm \mathrm{SD}\end{array}$ & $44.9 \pm 6.7 \mathrm{~mm}$ & $32.7 \pm 2.8 \mathrm{~mm}$ & $<.0001$ \\
$\begin{array}{l}\text { Age, mean } \pm \text { SD } \\
\text { AWS, median }\end{array}$ & $51.3 \pm 15.5 \mathrm{y}$ & $58.7 \pm 7.6 \mathrm{y}$ & .034 \\
$\quad$ (interquartile range) & $6.0(3-9)$ & $3.0(1-4)$ & $<.001$ \\
$\begin{array}{l}\text { Stenotic BAV } \\
\text { Regurgitant BAV }\end{array}$ & $41.1 \%$ & $32.1 \%$ & $\mathrm{NS}$ \\
Mixed disease BAV & $41.1 \%$ & $46.4 \%$ & $\mathrm{NS}$ \\
Arterial hypertension & $16.4 \%$ & $21.4 \%$ & $\mathrm{NS}$ \\
& $27.0 \%$ & $25.0 \%$ & $\mathrm{NS}$
\end{tabular}

$S D$, Standard deviation; $A W S$, aortic wall score; $B A V$, bicuspid aortic valve; $N S$, not significant. 
TABLE 3. Histopathologic changes in ascending aorta wall in type $A$ and type $B$ cusp fusion

\begin{tabular}{lrcc}
\hline & Type A & Type B & \\
Histopathologic change & $\mathbf{N = \mathbf { 8 5 }}$ & $\mathbf{n = 2 8}$ & $\boldsymbol{P}$ \\
\hline Fibrosis & $67.0 \%$ & $21.4 \%$ & $\leq .01$ \\
& $(0.9)$ & $(0.2)$ & \\
Atherosclerosis & $56.4 \%$ & $42.8 \%$ & $\mathrm{NS}$ \\
& $(1.0)$ & $(0.7)$ & \\
Medionecrosis & $80.0 \%$ & $42.8 \%$ & $<.025$ \\
& $(1.7)$ & $(0.9)$ & \\
Cystic medial necrosis & $90.5 \%$ & $57.1 \%$ & $<.025$ \\
& $(2.1)$ & $(1.0)$ & \\
SMC orientation & $67.0 \%$ & $35.7 \%$ & $\leq .01$ \\
& $(0.7)$ & $(0.3)$ & \\
Elastic fragmentation & $83.5 \%$ & $50.0 \%$ & $<.025$ \\
& $(0.8)$ & $(0.4)$ & \\
Inflammation & $27.0 \%$ & $7.1 \%$ & $\leq .05$ \\
& $(0.3)$ & $(0.1)$ & \\
\hline
\end{tabular}

$N S$, Not significant; $S M C$, smooth muscle cell. Numbers in parentheses show mean grading value for each histopathologic feature.

study of children with BAV, Fernandes and coworkers ${ }^{11}$ observed a prevalence of $70 \%$ and $28 \%$ for type A and type B fusion, respectively. Moreover, in both articles ${ }^{10,11}$ type $\mathrm{C}$ was the least common morphologic variant. Sievers and Schmidtke ${ }^{12}$ recently proposed a classification system for BAV based on the number of raphes. In the present series, we observed BAV with only 1 raphe (Sievers type 1) in all cases. In Sievers series, type 1 BAV accounted for $88 \%$ of cases and the distribution of cusp fusion patterns was comparable to our observations.

Histopathologic changes in the ascending aorta, predisposing one to aneurysm development and dissection, are well documented in BAV. ${ }^{5-7}$ The results from our series confirm the presence of pathologic alterations in the wall of the ascending aorta. Moreover, we observed that the severity of changes in the aortic wall relates to the degree of aortic dilatation, as reported by Matthias Bechtel and coworkers. ${ }^{5}$

It has been suggested that a relationship exists between BAV morphology and different cardiac abnormalities, valvar function, and aortic root dilation. ${ }^{11}$ Aortic stenosis or regur- gitation is observed most often in patients with type B cusp fusion, whereas the majority of patients with aortic coarctation and a lesser degree of valve disease had type $\mathrm{A}$ fusion. ${ }^{11}$ These observations were recently confirmed by Ciotti and coworkers. ${ }^{13}$ To the best of our knowledge, the association between coronary cusps fusion and a more severe degree of degeneration of the ascending aorta is a novel finding. We did not observe a statistically significant difference between type A and type B cusp configurations in terms of ascending aorta diameter, BAV disease, and known risk factors for aortic degeneration, such as arterial hypertension. However, mean age was significantly lower in the type A fusion group. Therefore, it can be argued that the more severe aortic wall degeneration observed in type A configuration is not related to the degree of ascending aorta dilatation or to other known factors. Nevertheless, the aortic root diameter was within the normal range in type B fusion, whereas it was significantly larger in type A fusion. Such a difference may suggest a heterogeneous localization of aortic disease among cusp fusion patterns. This finding deserves further study by examining tissue samples from the Valsalva sinuses.

The pathogenesis of aortic dilatation in patients with BAV is still unclear. Moreover, it is controversial if such a mechanism is related to intrinsic congenital defects or to an acquired injury resulting from the ascending aorta wall being secondary to BAV flow patterns. It has been speculated that the association between cusp arrangement and ascending aorta disease may be explained by abnormal patterns of development of the neural crest cells, which contributes to the embryogenesis of both cardiac structures, ${ }^{14,15}$ or by a peculiar hemodynamic effect of each BAV anatomic type, acting since fetal life and resulting in different degrees of stress-induced aortic degeneration. Cotrufo and coworkers ${ }^{7}$ reported an asymmetric pattern of matrix protein expression in BAVassociated aortic dilatation, consistent with the asymmetry in wall-stress distribution, and differences between patients with stenotic BAV compared with regurgitant BAV in terms of protein expression and content in the aortic wall.

The finding that patients with type A fusion had a more severe aortic wall degeneration compared with patients with type B fusion, despite similar aortic size, has several

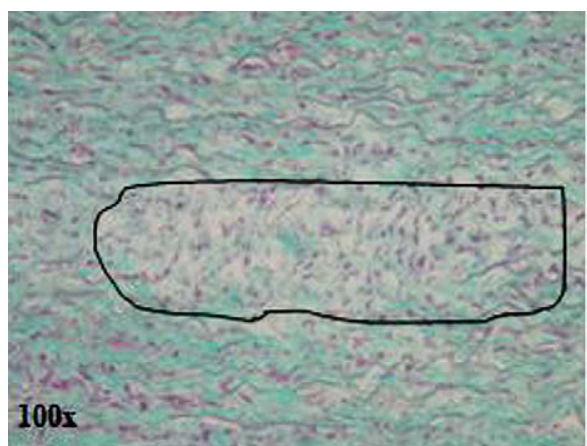

A

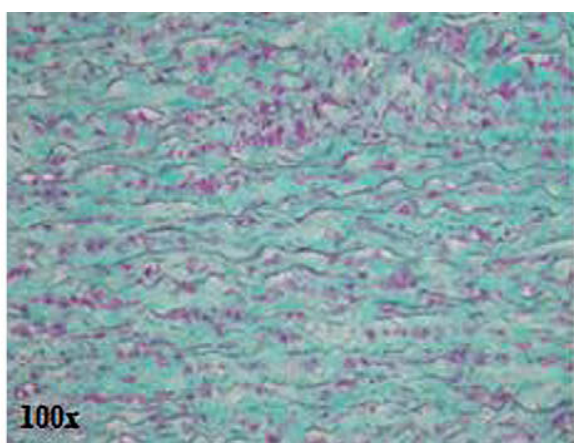

B
Figure 3. A, Histologic section from the ascending aorta in a patient with type $A$ valve anatomy (AWS 8): severe cystic medial necrosis, grade 3 (circled area), and fragmentation of elastic fibers. B, Histologic section from the ascending aorta in a patient with type $B$ valve anatomy (AWS 3): fibrosis, fragmentation of elastic fibers, and misalignment of smooth muscle cells. Five-micron sections, Masson trichrome elastic stain, magnification $100 \times$. 
explanations. First, type A group data have an influence on the result of the correlation analysis greater than type B group data. It is likely that this is related to the different sample size in the 2 groups. The type B group was small; consequently, a correlation analysis only on type B data was not so informative. We hypothesize that the correlation between diameter and AWS may be different between type A and type B. Such a difference could be explained by a still unknown factor, acting on the status of the aortic tissue and related to developmental mechanisms that determine the anatomy of the BAV.

\section{Clinical Implications}

Data from different groups ${ }^{2,4}$ demonstrated that patients with $\mathrm{BAV}$ are at increased risk for aortic complications and that aortic valve replacement does not prevent progressive aortic dilatation. ${ }^{4}$ Borger and coworkers ${ }^{3}$ suggested that patients undergoing operations for BAV disease should be considered for concomitant replacement of the ascending aorta if the diameter is $4.5 \mathrm{~cm}$ or greater. Recent guidelines from the American College of Cardiology/American Heart Association confirm such a strategy. ${ }^{16}$ However, not all patients with BAV will develop aortic dilatation over time. Nistri and coworkers ${ }^{17}$ observed a $52 \%$ prevalence of aortic dilatation in a series of young patients with normally functioning BAV. Techniques for real-time intraoperative histologic grading of the aortic wall, requiring less time than standard aortic valve replacement, are not yet available. Moreover, there is still limited knowledge about clinical or echocardiographic features that may help to identify patients with BAV who are prone to aortic dilatation over time. Novaro and coworkers ${ }^{18}$ observed that male gender, sinus diameter, and, as a trend, right/noncoronary cusp fusion predicted dilation of the ascending aorta in aortic regurgitation, whereas in aortic stenosis only age and sinus dimension were significant predictors. However, their study population differs from ours in that the mean diameter of the mid-ascending aorta was lower $(41.0 \mathrm{~mm})$ and only $18 \%$ of patients underwent replacement of the ascending aorta.

In patients with BAV disease and type A fusion, the presence of more severe histopathologic features at a younger age, in addition to a degree of aortic dilatation similar to that in older patients, and a significantly larger aortic root suggest a more accelerated and-may be-malignant aortopathy. The association with a more severe degree of aortic disease suggests the opportunity of closer follow-up in patients with type A BAV.

\section{Limitations}

The aim of the study was to investigate aortic disease from a morphologic point of view. Therefore, our results are not yet supported by a follow-up to evaluate the clinical effect of anatomic features on the long-term prognosis. Another limitation of the study is its retrospective design. Because of the low prevalence of type $\mathrm{C}$ fusion, we were unable to make any inference about such fusion pattern. Moreover, aortic diameter was expressed as absolute value. We recognize that indexing the aortic diameter to the body surface area could be useful for decision making in patients with exceptionally small $\left(<1.6 \mathrm{~m}^{2}\right)$ or large $\left(>2.2 \mathrm{~m}^{2}\right)$ body size. Nevertheless, we did elect to refer to absolute values for the following reasons: Current clinical practice still refers mainly to absolute values to evaluate surgical indications, and most of our patients had a body surface area within normal range $\left(1.7-2.0 \mathrm{~m}^{2}\right)$. Tissue samples have been harvested only from the mid-ascending aorta. Therefore, we are unable to speculate about the topography of the degenerative aortic changes. The conclusions of our study do not concern the totality of the patients with BAV. In fact, only a few patients develop aortic dilatation ${ }^{17}$ and dissection. ${ }^{1}$ Moreover, our study population is selected, because it is composed of patients with both severely diseased BAV and dilated aorta.

\section{Conclusions}

In patients with BAV, we observed a statistically significant association between type A valve anatomy and both a more severe degree of wall degeneration in the ascending aorta and dilatation of the aortic root at a younger age than in type B anatomy. Such evidence supports a closer follow-up of patients with fusion of the coronary cusps. There is a compelling need for further studies on the relationships among BAV, aortic wall status, and clinical events to identify patients at increased risk of aortic complications.

\section{References}

1. Ward C. Clinical significance of the bicuspid aortic valve. Heart. 2000; 83:81-5.

2. Russo CF, Mazzetti S, Garatti A, Ribera E, Milazzo A, Bruschi G, et al. Aortic complications after bicuspid aortic valve replacement: long-term results. Aortic complications after bicuspid aortic valve replacement: long-term results. Ann Thorac Surg. 2002;74:S1773-6; discussion S1792-9.

3. Borger MA, Preston M, Ivanov J, Fedak PW, Davierwala P, Armstrong S, et al. Should the ascending aorta be replaced more frequently in patients with bicuspid aortic valve disease? J Thorac Cardiovasc Surg. 2004;128:677-83.

4. Yasuda H, Nakatani S, Stugaard M, Tsujita-Kuroda Y, Bando K, Kobayashi J, et al. Failure to prevent progressive dilation of ascending aorta by aortic valve replacement in patients with bicuspid aortic valve: comparison with tricuspid aortic valve. Circulation. 2003;108(Suppl 1): II291-4.

5. Matthias Bechtel JF, Noack F, Sayk F, Erasmi AW, Bartels C, Sievers HH. Histopathological grading of ascending aortic aneurysm: comparison of patients with bicuspid versus tricuspid aortic valve. $J$ Heart Valve Dis. 2003;12:54-61.

6. de Sa M, Moshkovitz Y, Butany J, David TE. Histologic abnormalities of the ascending aorta and pulmonary trunk in patients with bicuspid aortic valve disease: clinical relevance to the Ross procedure. $J$ Thorac Cardiovasc Surg. 1999;118:588-94.

7. Cotrufo M, Della Corte A, De Santo LS, Quarto C, De Feo M, Romano G, et al. Different patterns of extracellular matrix protein expression in the convexity and the concavity of the dilated aorta with bicuspid aortic valve: preliminary results. J Thorac Cardiovasc Surg. 2005;130:504-11. 
8. De Paepe A, Devereux RB, Dietz HC, Hennekam RC, Pyeritz RE. Revised diagnostic criteria for the Marfan syndrome. Am J Med Genet. 1996;62:417-26.

9. Angelini A, Ho SY, Anderson RH, Devine WA, Zuberbuhler JR, Becker AE, et al. The morphology of the normal aortic valve as compared with the aortic valve having two leaflets. $J$ Thorac Cardiovasc Surg. 1989;98:362-7.

10. Sabet HY, Edwards WD, Tazelaar HD, Daly RC. Congenitally bicuspid aortic valves: a surgical pathology study of 542 cases (1991 through 1996) and a literature review of 2,715 additional cases. Mayo Clin Proc. 1999;74:14-26.

11. Fernandes SM, Sanders SP, Khairy P, Jenkins KJ, Gauvreau K, Lang P, et al. Morphology of bicuspid aortic valve in children and adolescents. $J$ Am Coll Cardiol. 2004;44:1648-51.

12. Sievers HH, Schmidtke C. A classification system for the bicuspid aortic valve from 304 surgical specimens. J Thorac Cardiovasc Surg. 2007; 133:1226-33.

13. Ciotti GR, Vlahos AP, Silverman NH. Morphology and function of the bicuspid aortic valve with and without coarctation of the aorta in the young. Am J Cardiol. 2006;98:1096-102.

14. Kappetein AP, Gittenberger-de Groot AC, Zwinderman AH, Rohmer J, Poelmann RE, Huysmans HA. The neural crest as a possible pathogenetic factor in coarctation of the aorta and bicuspid aortic valve. J Thorac Cardiovasc Surg. 1991;102:830-6.
15. Anderson RH, Webb S, Brown NA, Lamers W, Moorman A. Development of the heart: (3) formation of the ventricular outflow tracts, arterial valves, and intrapericardial arterial trunks. Heart. 2003;89: 1110-8.

16. Bonow RO, Carabello BA, Kanu C, de Leon AC Jr, Faxon DP, Freed MD, et al., American College of Cardiology/American Heart Association Task Force on Practice Guidelines; Society of Cardiovascular Anesthesiologists; Society for Cardiovascular Angiography and Interventions; Society of Thoracic Surgeons. ACC/AHA 2006 guidelines for the management of patients with valvular heart disease: a report of the American College of Cardiology/American Heart Association Task Force on Practice Guidelines (writing committee to revise the 1998 Guidelines for the Management of Patients With Valvular Heart Disease): developed in collaboration with the Society of Cardiovascular Anesthesiologists: endorsed by the Society for Cardiovascular Angiography and Interventions and the Society of Thoracic Surgeons. Circulation. 2006;114:e84-231.

17. Nistri S, Sorbo MD, Marin M, Palisi M, Scognamiglio R, Thiene G. Aortic root dilatation in young men with normally functioning bicuspid aortic valves. Heart. 1999;82:19-22.

18. Novaro GM, Tiong IY, Pearce GL, Grimm RA, Smedira N, Griffin BP. Features and predictors of ascending aortic dilatation in association with a congenital bicuspid aortic valve. Am J Cardiol. 2003; 92:99-101. 